\title{
Stoic and Sentimental: The Emotional Work of the Edwardian Greetings Postcard
}

\author{
PETER GILDERDALE
}

\begin{abstract}
For both Edwardian migrants and First World War soldiers, communicating home involved a choice as to the appropriate emotional regimes to use. Should they display stoic reserve, or communicate sentimental feeling? Research on correspondence has normally focused on letters, but this paper examines how emotion was dealt with through the multimodal medium of the greetings postcard. It argues that whilst handwritten texts on postcards remained primarily stoic, the pre-packaged visual vocabulary on greetings postcards allowed users to send strongly emotional arguments for the maintenance of their relationships without ever having to put these into their own words. Postcards, it seems, gave the Edwardians the option of being both stoic and sentimental.
\end{abstract}

\section{Introduction}

Most people, even today, experience some degree of emotional upheaval when finding themselves half a world away from loved ones for any extended period. Such prolonged separations - sans Skype and cell phone - were particularly common for Edwardian New Zealanders. During a period of fluctuating mobilities, the first fifteen years of the twentieth century would see nearly 300,000 people sunder connections with friends and family to move southwards to New Zealand, while the subsequent flood of soldiers northward during the First World War created further hemispherical divides. ${ }^{1}$ Migrants and soldiers alike were thus faced with the issue of trying to preserve what Angela McCarthy has characterised as "robust and resilient ties" with their existing networks. ${ }^{2}$ This situation reinforced the centrality of the institution of the Post Office in assisting migrants to minimise the emotional damage done by distance. Hitherto, the study of migrant correspondence has concentrated largely on letters, their content and their functions. ${ }^{3}$ Despite recent interest in the masculine emotions displayed in war correspondence, as a whole there has been relatively little unpacking of the evidence, or otherwise, of emotion in these. ${ }^{4}$ Postcards, on the face of it, would appear to be a rather less promising source than letters for providing evidence of whether their writers displayed stoical resolve or sentimental excess in the ways they maintained their contacts, and if one looks at the textual evidence alone, this proves to be the case. However, after noting methodological issues and discussing the emotional cultures that fostered stoicism and sentiment, this paper goes on to argue that the complex mix of visual and verbal elements found in some types of postcard allowed users to engage in multiple emotional strategies. These involved maintaining a stoic everyday voice, while simultaneously using a prefabricated, ritualised, symbolic and sentimental visual vocabulary to maintain the intensity and advocate for the reality of their virtual relationships.

\section{Methodology}

Interpreting emotion from an atypical source like the postcard inevitably requires some methodological explanation. This study utilises cards found not in archives but collected from online auction sites, as these provide a more broadly representative sample. ${ }^{5}$ However, the cards often lack context. We cannot always know whether correspondents were writing to someone they could confidently expect to see again in six months, or whether they expected never to meet in person again. Nor can variations in the emotional tone of communication 
usually be read within their original context, not least because we normally do not know how recently the separation occurred. Secondly, we cannot know what was omitted from the record. ${ }^{6}$ Self-censorship means that it is not always clear whether certain writers were ashamed to admit experiencing certain feelings we might expect in the circumstances, or were simply not experiencing them. Part of this issue relates to a third problem encountered by emotion researchers. It is a matter of debate as to whether emotions can be understood as psychologically universal, culturally specific, or simply contingent; whether they are inbuilt faculties of the human species, or conditioned responses to specific cultural or individual contexts. ${ }^{7}$ A measure of the potential for confusion can be seen by the way our understanding of expressions of nostalgia - the term used for homesickness - has changed over time. Whilst we read the effects of excessive longing for something lost as symptomatic of a psychological state, a century ago it was regarded as a physical disorder. ${ }^{8}$

\section{Emotional Cultures}

These problems are exacerbated by a considerable lack of certainty as to the way that emotional cultures have worked. Finding out what emotional regime was adopted by emigrants or soldiers, as they faced the spectre of 13000 miles between them and loved ones, is no easy matter. Dislocation triggered what Lauren Berlant has termed an "affective event," whereby the "sensorium of everyday life" was disrupted, and a new normality needed to be established. ${ }^{9}$ Even if the decision to emigrate was a deliberate decision by the wider family, ${ }^{10}$ immigrants still had to work through a sense of loss and grief, akin to that of bereavement, which would have been felt in proportion to the strength of each relationship. The fact that the absentee was still alive, and a parallel old normality still existed, encouraged what David Gerber describes as a "transnational imaginative culture." been lost, but also included the possibility of being re-united in the future. Grief, longing and hope, therefore, all figure in the resolution process. However, the overarching emotional regime that this discussion hinges around is whether the appropriate response to absentee longing was to express it or endure it, two options that were already well rehearsed within the Anglo-world by the Edwardian period, and their relationship needs to be fleshed out before we can appreciate the choices made by postcard users.

\section{Stoicism and Sentiment}

Stoicism, with its focus on rational control of the passions, and sentimentality, with its courting of emotion, are usually framed in oppositional terms, but this does not mean they were unrelated in practice. Indeed, as William Reddy points out, within eighteenth-century sentimental culture, it was believed that emotion and reason could coalesce. This communion was, according to Reddy, dramatically curtailed by the French Revolution, after which a split occurred between art, where emotion was acceptable, and public life, where reason and an honour-based, classical approach grounded in Roman stoicism reigned. ${ }^{12}$ This reclamation of a self-disciplined masculine ideal from the alternative "man of feeling" model resulted in attacks on feminising sentiment increasing from the 1860s, with science and empathy gradually replacing affect and sympathy in modernist discourse. ${ }^{13}$

Whilst stoicism steadily gained ground in public discourse, Reddy acknowledges that sentimentalism remained much more strongly embedded in private life. ${ }^{14}$ According to Peter Stearns (writing about the United States) emotional openness remained a desirable interpersonal quality until at least the $1920 \mathrm{~s} .{ }^{15}$ Within the family unit, it is evident that Reddy's public sphere segue from sentiment to stoicism played out less clearly. ${ }^{16}$ In part, a more sentiment-friendly private sphere would be easy to attribute to issues of both interiority and of gender. Women were stereotypically (though not necessarily accurately) seen as more emotional and less controlled. ${ }^{17}$ Yet even in male culture, stoicism struggled to become the 
dominant discourse. John Tosh identifies two dominant regimes - what he calls the distant and the fond father - within middle-class homes. These hinged on the extent to which paternal duty was expressed through loving words and actions, or through moral discipline and exemplary conduct. ${ }^{18}$ Tosh argues that, by the end of the nineteenth century, the male backlash against feminised domesticity had gained considerable force, though this is not reflected in largescale changes of language, and the extent to which both models of manhood could co-exist in the gap between imagination and reality should not be underestimated. ${ }^{19}$

The debate is further complicated by the fact that stoicism, in its more general sense of the self-censoring of raw emotions, was not just a middle-class phenomenon. Emotional reticence was pronounced in settler societies like New Zealand, where egalitarian male sociability was often dismissive of unmanly emotion. ${ }^{20}$ Such forms of staunchness may in part draw on the middle-class stoical tradition, but probably also owed much to a working-class emotional culture that had long practiced stoical restraint in the face of hardship. ${ }^{21}$ Admittedly, this restraint found relief in melodramatic and sentimental entertainments that provided emotional abundance, or what Bourdieu describes as "maximum effect for minimum cost," but it is the response to the personal situation of being parted that is of concern here. ${ }^{22}$ Julie-Marie Strange, who has made a careful study of working-class responses to death, points out that fluent verbal expressions of grief are not the only measure of emotion, and a staunch, stoic and inarticulate response to emotionally-charged situations should not be read as necessarily an indicator of lack of feeling. Indeed, she argues, in the face of intense emotional distress, language is quite inadequate. ${ }^{23}$

\section{The Emigrant and the postcard}

Nevertheless, the first immigrants to New Zealand, regardless of class, had little option but to make language work for them. Sporadic letters - limited by either expense or infrequent shipping - were the only available postal option to maintain connections with those left behind, and to stave off the gnawing spectre of being forgotten. ${ }^{24}$ The pain of leaving home, with its attendant anxieties, uncertainties, destabilisation and hardships was, unsurprisingly, dealt with differently by different people. Easy generalisations, even between genders, are not supported by evidence. ${ }^{25}$ This sense of a range of reactions is evident when Porter and Macdonald note that amongst (mostly well-heeled) settler women writing letters from New Zealand, the hardships encountered were "not necessarily, or even usually borne with stoicism or cheerfulness." ${ }^{26}$ At the same time, the conventions of social exchange, and the desire not to distress recipients provided a brake on unrestrained expressions of that emotion. ${ }^{27}$ In letters, therefore, there seems to be no sure way of distinguishing whether the reticence and telling silences emanated from stoical willpower, sentimentally inspired courtesy, or linguistic paralysis.

By the Edwardian period, several factors had come together to slightly lessen, if not extinguish, the isolation felt by new immigrants. While the telegraph assisted the general sense of connectedness, everyday contact was helped by improvements in shipping. The time lag between knowing whether a piece of communication had been received by those at home had reduced from up to a year to around three months. ${ }^{28}$ And in 1901 the New Zealand government finally bowed to pressure and entered the international Penny Post agreement. ${ }^{29}$ Consequently, price became much less of a barrier to frequent communication. People wishing to maintain contact with absent friends and family also now had the alternative of what Julia Gillen has described as a "new epistolary space" instead of the traditional letter, and one that placed fewer demands on their literary prowess. ${ }^{30}$ In 1898 the New Zealand government had followed a growing international trend, soon to be dubbed the "postcard craze," and allowed the sending of privately printed pictorial postcards. ${ }^{31}$ 


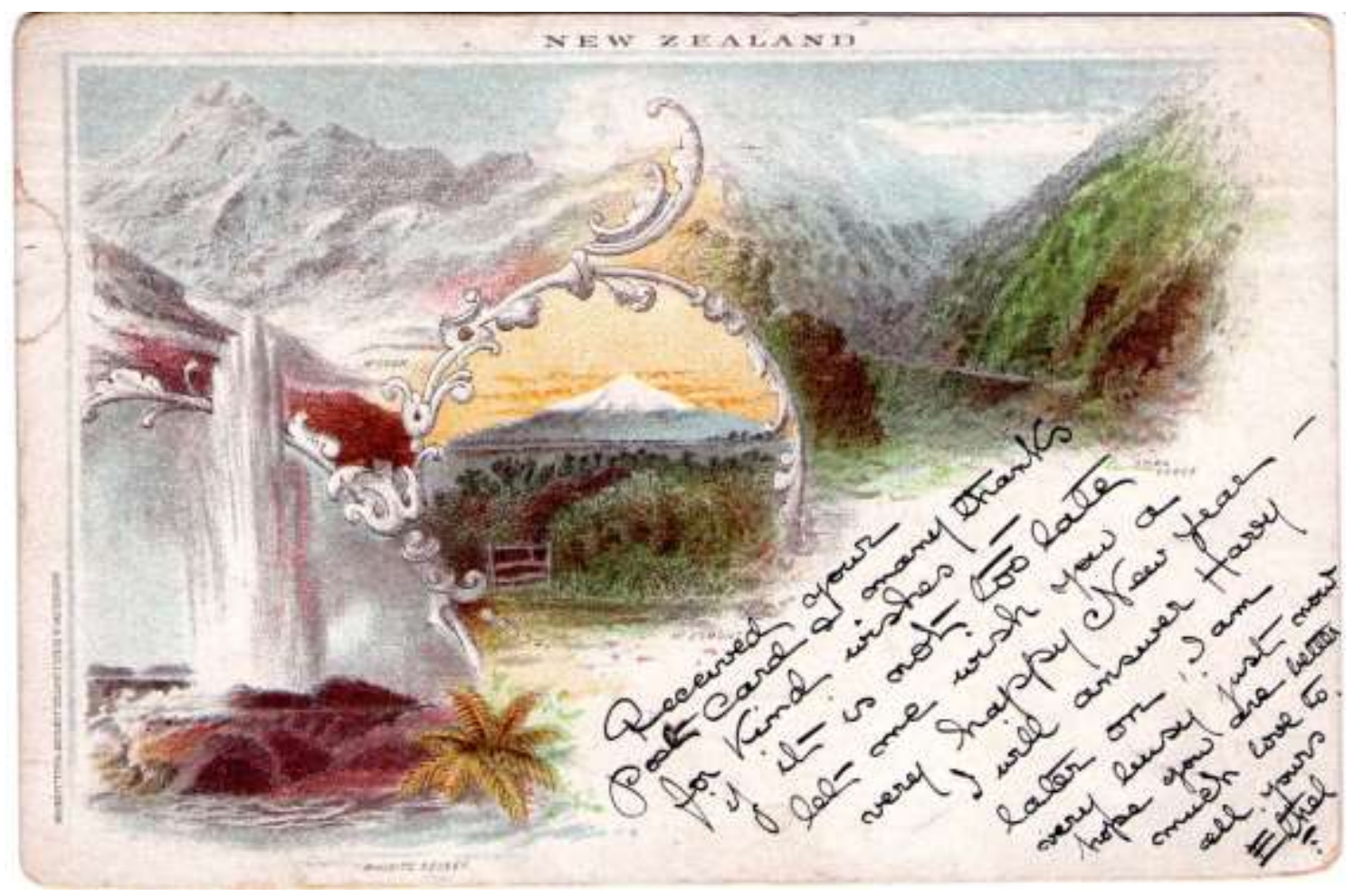

Figure 1: This New Zealand Government issued card was printed in England by Waterlow and Sons, and was intended to promote the country as a tourist destination. It was widely used in the years following its issue in 1898.

It has been estimated that during the first twenty years of the $20^{\text {th }}$ century the postcard craze accounted for over 200 billion postcards being sent worldwide. ${ }^{32}$ It was ubiquitous, and can be compared to Twitter in terms of both its impact and function. ${ }^{33}$ However, whilst we now have a clear sense that the postcard is a quick, no fuss medium for holiday communication, this was not its function for much of the craze. Introduced during the $1870 \mathrm{~s}$, it was intended primarily for business rather than personal use. ${ }^{34}$ Only during the 1890 s, initially in Germany and gradually further afield, did the pictorial card take hold. Figure 1 shows New Zealand's earliest pictorial postcard. Despite not having exactly the format we expect of today's card, with its message space limited to the front, it still conforms broadly to our idea of the stereotypical postcard - a tourist image, with a prosaic, everyday message of greeting added by the sender. However, our contemporary understanding of postcards as holiday souvenirs is a very considerable impediment to understanding the complexity of the Edwardian variety.

Although Edwardian postcards began with tourism in mind, during the main postcard craze users co-opted postcards for a wide range of communication and social networking functions, and manufacturers supplied a much wider range of cards than the traditional tourist views ${ }^{35}$ Celebrity cards, animal cards, pictures of children, comic cards, art reproductions and a raft of other types catering to virtually every conceivable taste flooded the market. ${ }^{36}$ Traditional Christmas, Birthday and Valentine greeting cards were supplemented by cards that allowed you to wish people luck, to joke about their habits, and even to talk to the condition of being parted. That is precisely what one highly popular genre, the Hands Across the Sea card (Figure 2), was designed to do. ${ }^{37}$ While the act of sending a tourist photo of a place could turn an emotionally neutral card into a tangible token of remembrance, the Hands Across the Sea card actively foregrounded aspects of distance, absence and the barriers between correspondents that are only implicit in other genres. The intent of the purchaser to use the

Journal of New Zealand Studies NS22 (2016), 2-18 
design for communicative purposes is, in this case, particularly clear. ${ }^{38}$ Hands cards were sufficiently popular to be used not only by immigrants but also by those within New Zealand who were parted by lesser, but still psychologically significant, distances.

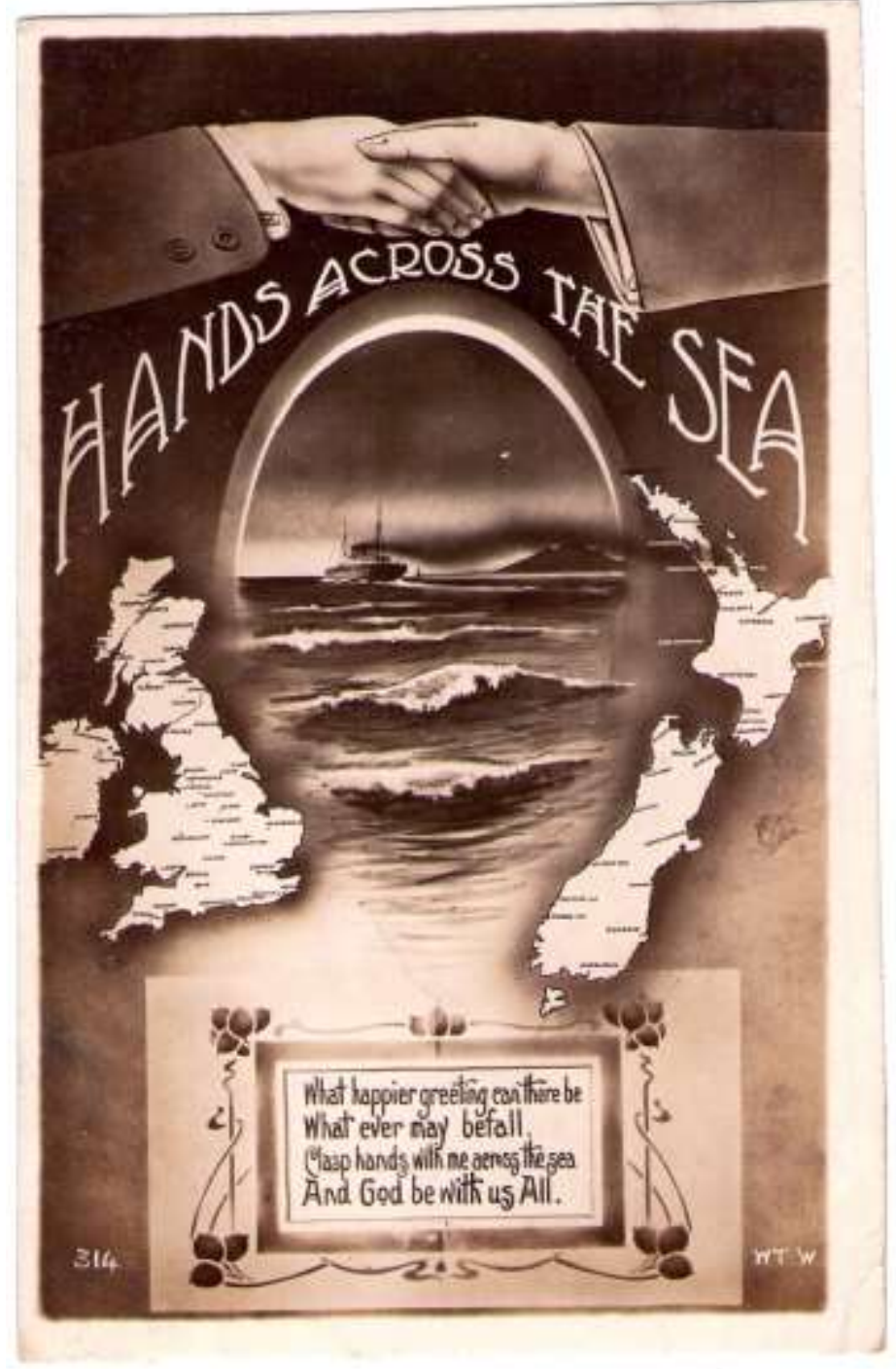

Figure 2: W. T. Wilson, Hands Across the Sea postcard, Auckland, 1909.

\section{Imagery}

The unifying feature of the Hands Across the Sea card is the emblem of the clasped hands. For Victorian and Edwardian immigrants a handshake was frequently the last physical contact with friends and family left behind. Its memory thus carried an affective connotation. The haptic link to the sentimental mode is further strengthened when one thinks of the way we describe melodramatic scenes as being "touching," and it is hardly coincidental that New Zealand's second most popular melodrama of this period was one called Hands Across the Sea by Henry Pettitt. ${ }^{39}$ As such, it is reasonable to suggest that people sending and receiving cards using this phrase, and depicting clasped hands, were using overtly melodramatic and sentimental means to send a clear message. ${ }^{40}$ By dint of the post, one could metaphorically stay in touch and the relationship could be the stronger for it. 
Though clasped hands were the symbol that defined the genre, it was only one of many other images, symbols and emblems utilised by card designers. In an epistolary context, the form of a letter could serve as a familiar anchor to situate and secure the correspondents. ${ }^{41}$ Similarly, visual forms could provide familiar elements to achieve the same purpose. Hands Across the Sea cards frequently incorporated images of ships, the sea and flower symbolism that functioned as part of a visual language which aimed to communicate emotion. ${ }^{42}$ Quite clearly, cards like figure 2 were intended to do the emotional work for users, both through the visual schema and the poetic sentiments which appear on most such cards.

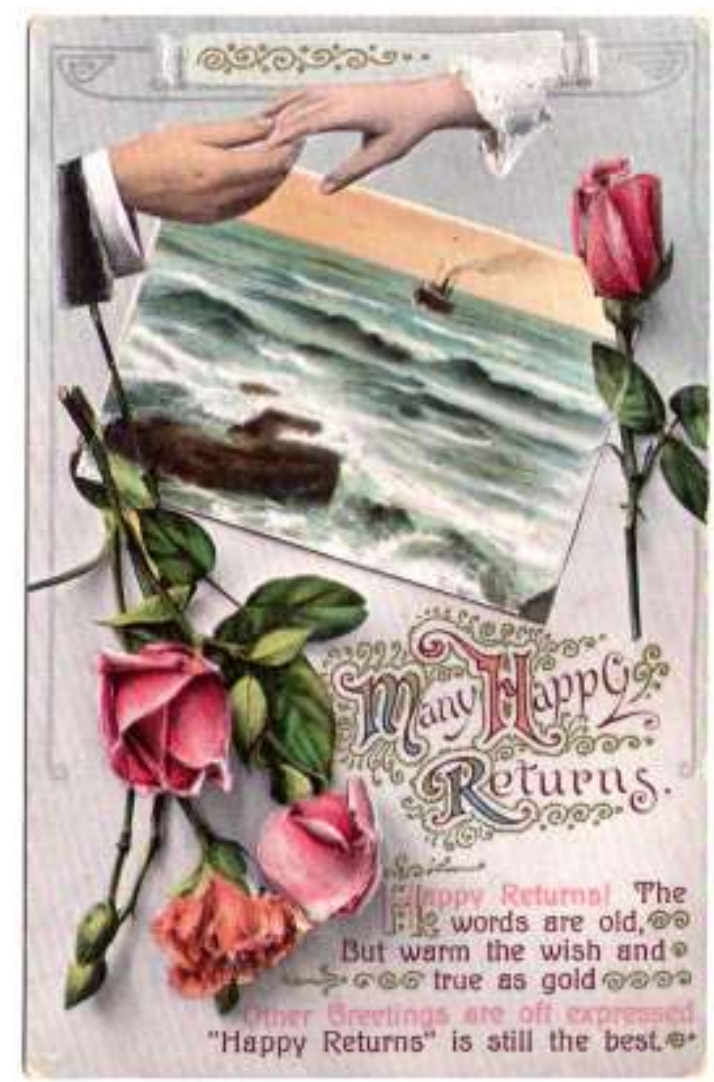

Figure 3: German printed card by an anonymous publisher. It was sent in 1914.

Some cards, like figure 3, were created to be flexible. While "many happy returns" suggests a birthday, the image of the sea and the open-ended poem leaves room for users to apply it as a Hands Across the Sea card, wishing returns that are spatial rather than temporal. Given such tactics, it comes as no surprise to find that many users, like the sender of figure 3 , did indeed allow the design to do the talking, in much the same way many people today are happy to send a signed Christmas card with no message as a token of regard. "With all the sentiments embodied on the reverse of this card," wrote Jack, as he sent a clasped hands birthday greetings to his sister Molly. ${ }^{43}$ And in Figure 2, Fred added little other than sincerity to the printed text by writing "May God bless You" on a card that very literally depicts the reality of emigration. In such cases it was the act whereby the sender selected and sent an appropriate greeting that mattered to the recipient, and served to revitalise the relationship, rather than the originality of the message. 


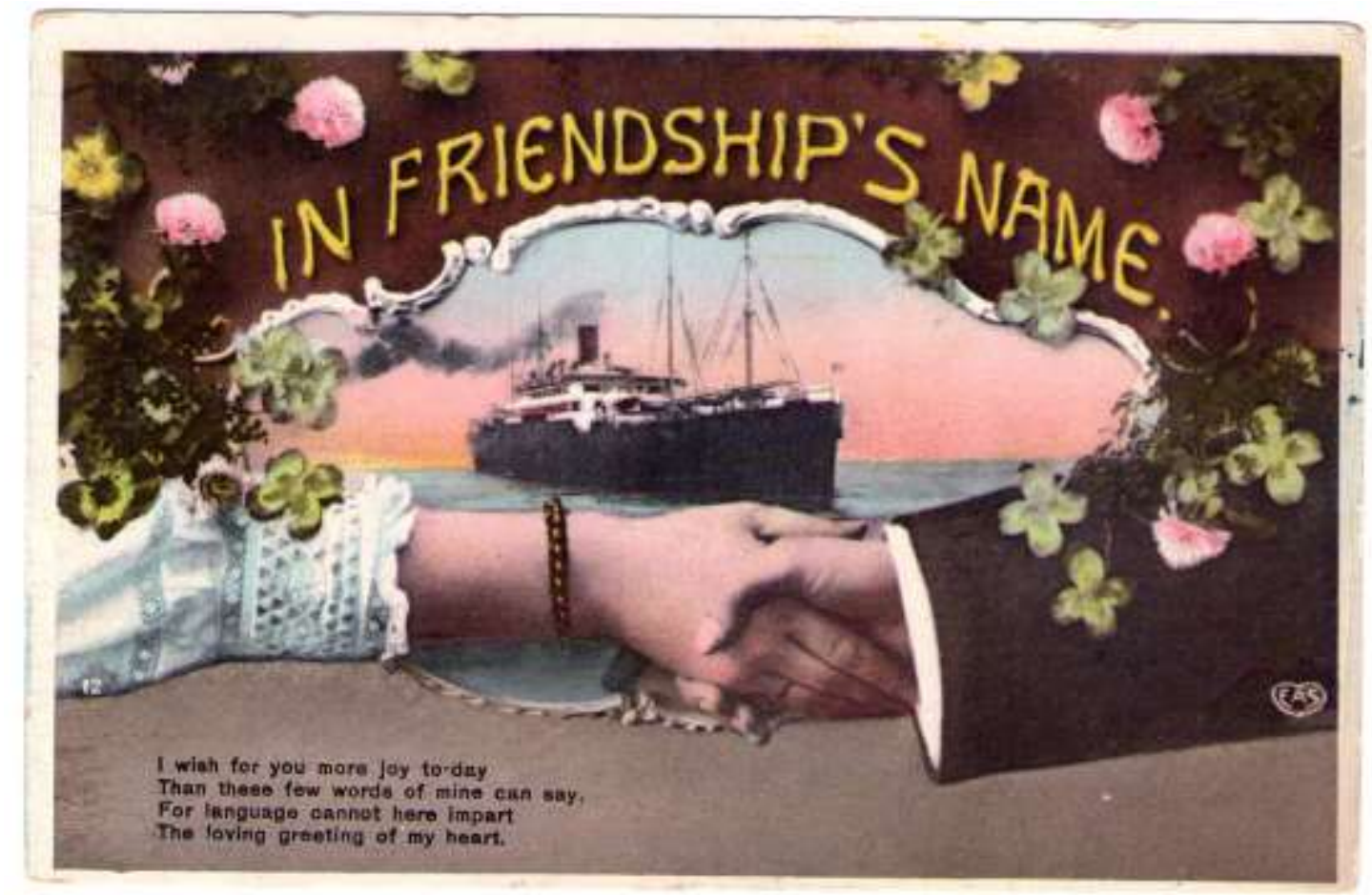

Figure 4: E. A. Schwertfeger \& Co. Clasped hands postcard, 1912, sent in New Zealand in 1914.

In other cases, the writer opted to use the message area more expansively. "Dear Lulla" writes a mother to her daughter on the reverse of Figure 4:

I think your card very pretty I hope you will like this you will think you are coming home to me when you look at the steamer I am longing to see you I am going to get a little Baby to mind so when you come home you can look after it and I am getting another one as well with love from $\mathrm{Mum}^{44}$

It would be easy to assume that this warm, motherly and emotional message would be enough to do the job, but this mother's coordination of text and imagery reveals more. She refers directly to the ship represented on the Figure 4, but other elements seem to have played a part in her selection. The lettering and border are done in the manner of cake decoration - sugary, celebratory and ideal for a child. And, although Lulla might not have understood some other references, it is likely that her mother was aware of the symbolic meanings these flowers have in the Victorian language of flowers, since they are here very apposite. ${ }^{45}$ Pansies symbolise "thoughts," carnations represent a mother's undying love and the four-leafed clover adds luck. 


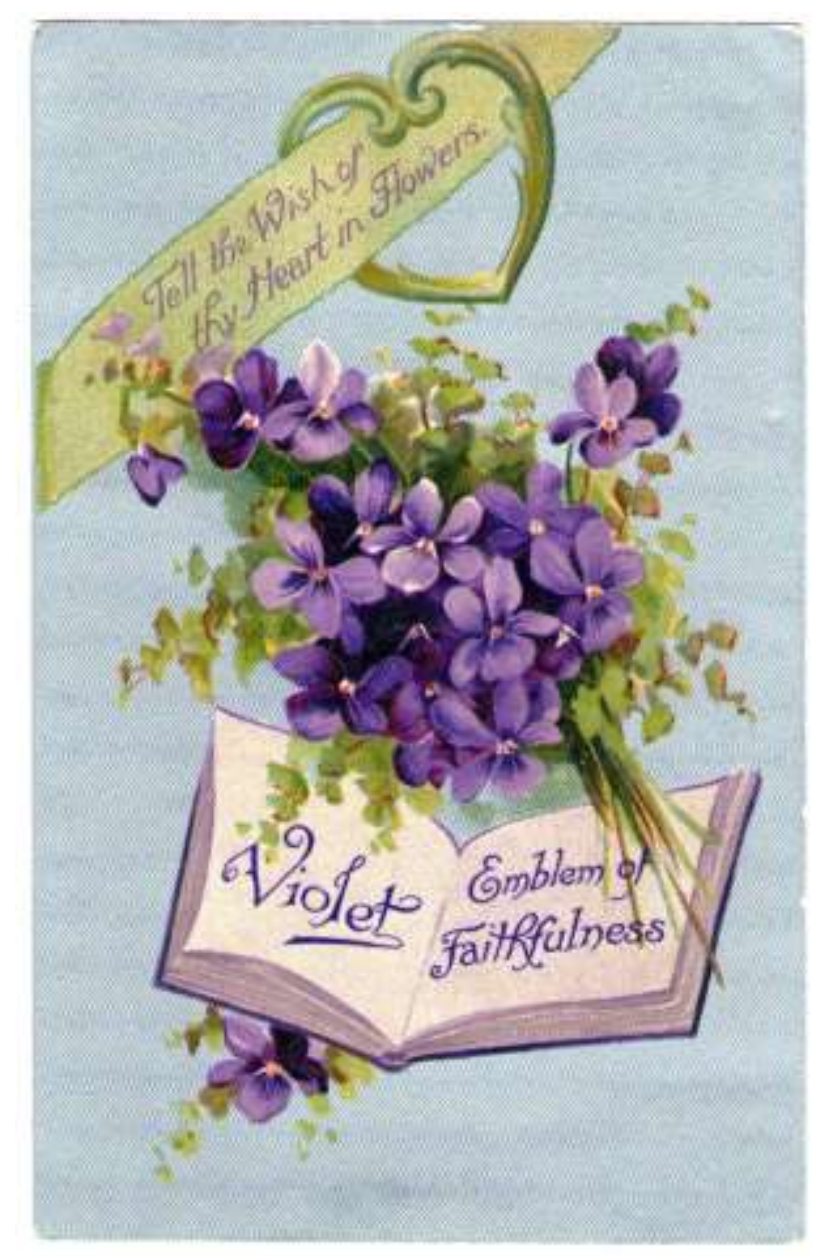

Figure 5: Birn Brothers Flower language card, c.1908

Using a visual language of this type is particularly significant given the way the printed text in Figure 4 avows the inadequacy of language to convey emotion. The imagery here is intended to function with specific and communicable meanings, right down to the prominent chain bracelet, which appears in many such depictions, and references the well-known phrase, often used in writing about emigration, "links that bind." 46

If the reader is inclined to think that too much is being read into these connotations, consider figure 5. It shows an example of a widespread genre which effectively taught the symbolism of flowers like the violet to users of both genders, encouraging them to use flower symbolism to "tell the wish of [their] heart."

We can see the violet's function as an emblem in another clasped hands card, (figure 6) which was written by a young Scottish lady, Nancy, to her absentee sweetheart, who, at the time of writing, was mining in New Zealand. The card seems to have been chosen deliberately, with violets emphasising the sender's faithfulness, and two strands of ribbon knotted together into a bow that represents the idea of continuing tight ties. The printed text also tries to aver the reality of this virtual medium, arguing that the emotional transfer effected via the token of this prefabricated card is genuine. 


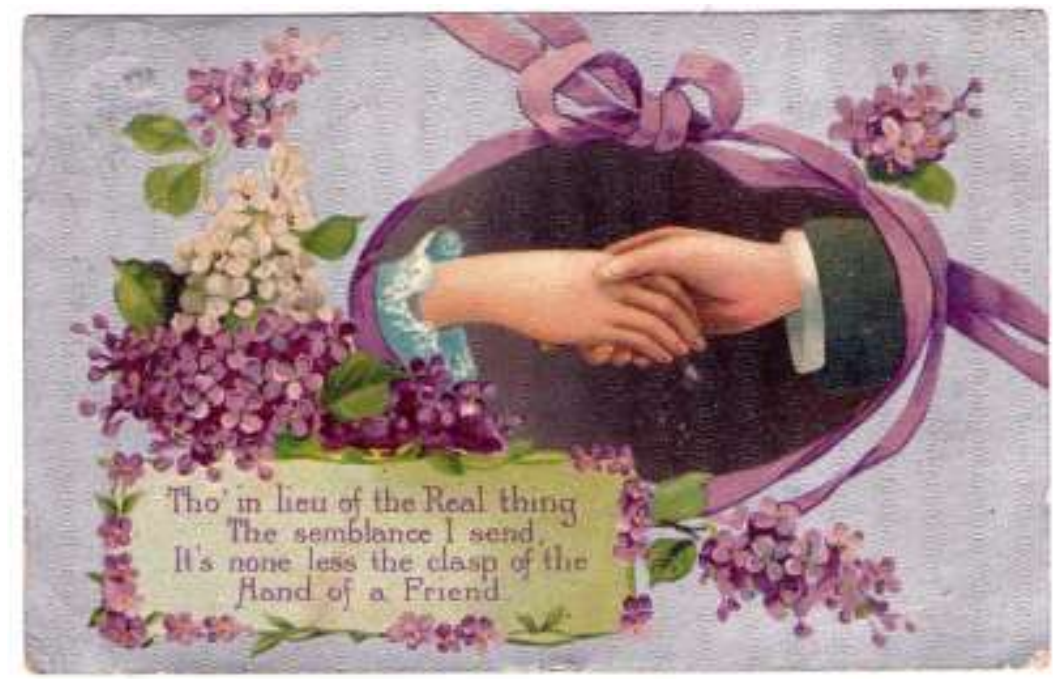

Figure 6: Birn Brothers clasped hands card, published c.1908, and sent in 1910.

\begin{abstract}
Tho in lieu of the Real thing
The semblance I send

It's none less the clasp of the

Hand of a Friend!
\end{abstract}

Nancy's handwritten text, at turns sarcastic, fearful, romantic and belligerent revolves around the greatest fear of the absentee - that of being forgotten.

Dear Sam I received your loving letter you never sent me. It was very nice too. I will be on your top if you don't write a big letter next time so don't forget it. I am worrying my heart away for you and mind you my wee heart is fu[11] I hope you have not forgot me. I wish you were here there are plenty of roses the garden is full such beauties You would not need Aggie Dickson to give you roses I would give you them for a change. I hope you have not done a bunk with the landladies Daughter My word if you have I will punch your blooming ear-ole for you Excuse this P.C. [post card] I will send letter next time I will draw to a close now I remain your lovin Swe[etheart] Nancy This is all I can share $\operatorname{xxxxxxx}$

The most common cause for displays of annoyance in cards, as in emigrant letters, was lack of reciprocity. ${ }^{47}$ Reciprocity is a quality that remains at the heart of working-class friendship retention practices. ${ }^{48}$ However, the apology for sending a card rather than a letter is also common. ${ }^{49}$ Although Kate Hunter points out that many letter writers struggled with expressing intimacy, letters were potentially more informative, more private and allowed for a greater emotional range. ${ }^{50}$ On the other hand, if one only looks at the user messages, postcard writers were more prosaic, and were seldom as forthcoming about feelings and insecurities as Nancy. Yet omission is also evidence in a discussion on stoicism, and it is thus worth exploring what these texts can reveal. 


\section{User Texts}

For this paper, I examined the texts of 75 Hands Across the Sea postcards which had been sent from overseas to New Zealand. ${ }^{51}$ Just over two thirds were sent by women - a fairly typical representation of postcard users. ${ }^{52}$ These cards were drawn from a larger collection, which included many HATS cards sent by people within New Zealand. I could find no discernible differences in tone or approach between the two sets of texts. Therefore it seems reasonable to assume that, despite not being the voices of the immigrants themselves, this sample of messages from friends and family who were experiencing the same degree of separation, would largely mirror the tone of the messages sent back to them. The 75 messages were categorised around the ideas of both function and tone. As greeting cards, one might expect greetings to play an important role, and just over half the texts were wholly greetings related. Of the 38 such cards, 27 used ritual greetings like "With best wishes for Christmas and the New Year," "With fond love \& best wishes," or "Many happy returns of your birthday." Such texts have been interpreted as "bowing" texts, which allow an absent family member to maintain solidarity with the family. ${ }^{53}$ However, whilst most greetings texts used tried-and-true formulae, eleven correspondents expanded and personalised their greetings: "Tons of love to you all \& a good old hand shake if we could. Toodloo," and "only a card with a xmas wish. I trust it was a very gay time for you and that you will spend your new year with your long looked to family God speed you in all." This minority of writers evidently felt the need to be expressive; however; the majority preferred ritualised messages, thus bearing out Emily West's contention that greeting card texts have a ritual rather than expressive function.$^{54}$ Indeed, two of the cards had no added text at all, relying entirely on the printed image and poem.

The use of prefabricated, ritualised texts is inevitably emotionally stoic. Regardless of the language used, they mask the sender's state of mind. Potentially the other 35 cards might show more. Twenty five of them contained more than 70 words, with the longest squeezing in 219. These cards were conversational, in an everyday way. The following text contains almost all the elements that emerged as themes. Sandwiched between ritual greetings are an expression of pleasure at receipt of correspondence, a desire for reciprocity, an assurance of wellbeing, a personalised greeting and a conversation point:

Dear Sandy I was very pleased to have your letter last week. Your writing has improved very much since you wrote last; I hope you will write again soon. We are all well here, hope this finds you all the same. We are thinking of starting harvest next week. Kind regards to all. Leenie

What is missing is any sense of it having, like Nancy's, an overtly emotional tone. Only six cards in this set did, with perhaps the most poignant being written by Aunt E. in 1910. "Dear Clara how I long to see your dear old face, you will know that Nellie will be coming out and what it will cost us, (not in money), wishing you all well \& love to all." Yet even this does not overplay its hand. The vast majority limit themselves to passing on information, and commenting on letters and on the receiver's life in general. Twenty-one involved discussions around reciprocity: "I have not had any mail from you now for ages but I am not blaming you for not writing. I do not know what is becoming of my letters." Twelve included (usually short) assurances of the sender's well-being: "they are all well here and busy with their nets."

The language used in the cards studied is also telling. The most common terms used were variations on the word "hope" (57 occurrences) and well-being (the word "well" occurs 41 times). Emotionally coloured terms in the cards studied were predominantly positive, such as "love" (45, though with all but three being used in ritual forms), "happy" ( 20 - all but one ritual), "nice" (17), "like" (15), "pleased" (13), "dear" (9 non-ritual uses, 61 ritual), "enjoy" (5), and "glad" (4). The words "sad," "unhappy" or variations on the word "fear" do not occur at all, "disappointed" occurs once, and there are five occasions where sorrow is expressed. 
However the fear involved in the words "forget" or "forgotten" appears ten times. Overall, it was quite clear that these handwritten texts were, if not overtly stoic, then decidedly reticent as to the sender's psychological state, especially if it was negative. The purpose of these messages was not self-disclosure, but rather what Kathryn Dindia labelled "relationship maintenance." 55

The handwritten text, however, is only part of the overall message. Figure 7 is, in many ways, exemplary of the way the medium could, should the sender so choose, operate as a coordinated multimodal whole. Elsie, a worker at Cadbury's factory in Birmingham, is writing to her friend Lil, who had moved to New Zealand.

My Dear Old Pal hoping it will finde you quite well \& fat \& plenty of work as I'am pleased to say that I am going on fine. I say Lil it is our Summer Party at Bournville tomorrow, \& by all account it will be great, as it is old Mr George's Silver Wedding. I wish you were hear remember me to Leon, \& Jack sends his love \& hopes you are well again. With heaps of love I remain your ever loving Pal Elsie

This is a typically chatty message, written in conversational mode, similar to that which David Fitzpatrick and others have noted in emigrant letters. ${ }^{56}$ It denies distance, in its own way, by behaving exactly as if Lil were in the room. Granted, phrases like "I wish you were here" and "your ever loving" index emotions, but they are ritualised, precisely because excessively personalised emotional language would subvert the impression of normality, and make Lil concerned. However the fact that Elsie is able to write with such nonchalance comes from the fact that the bulk of the emotional work is being done by the other side of the card (figure 7). "Absence makes the heart grow fonder," it proclaims, and goes on:

We often sit and talk of you

And wonder where you are

And what you may be doing

In your new home out afar

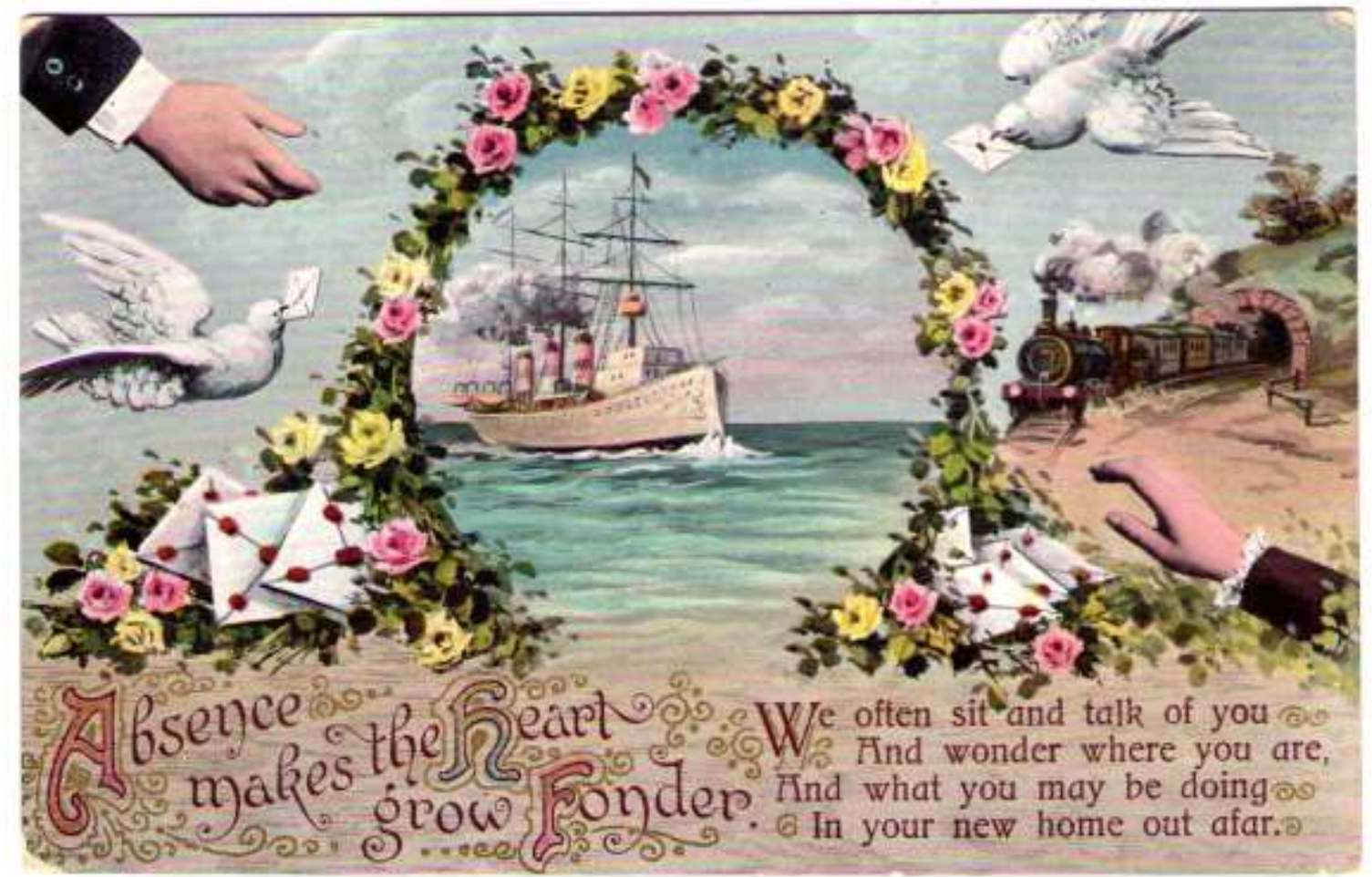

Figure 7: German Printed card by the same anonymous publisher as figure 3. It was sent by Elsie in 1913. 
In other words, "you are not forgotten, you are still with us." The imagery supports and expands this message. It talks eloquently of love via the roses. The sea, the steamer and the train indicate the sender's powerful will to connect from afar, as do the reaching hands and the envelopebearing doves. The seals on the envelope index the importance of the relationship. And the floral arch forms a horseshoe, turned downwards, as is usual in these cards, so that the luck will rain out onto the recipient.

\section{Communicating emotion}

For academics, there is something rather disconcerting about this reliance on commercial imagery. The lack of originality and the sentimentality make it natural to define it within the narrative of kitsch, and to see it as a pernicious commercial takeover of the emotionally expressive function of communication. ${ }^{57}$ Prefabrication is here seen as inauthentic. Emily West, however, convincingly counters this by arguing that appeals to authenticity are characteristic of those with higher cultural capital whereas those with less cultural capital are more likely to use ritualised means to index relationships. ${ }^{58}$ While the upper classes eschewed postcards, greetings cards manufacturers knew that their audience came from those classes less likely to object to sending or receiving prefabricated messages.

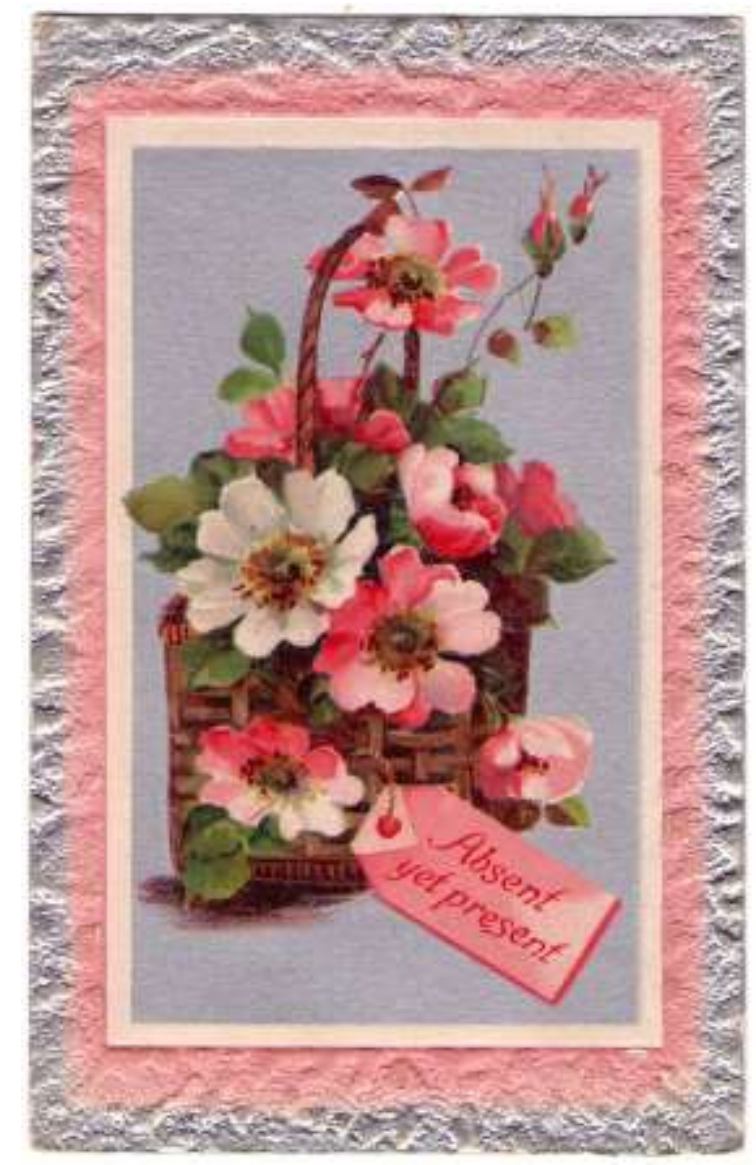

Figure 8: Birn Brothers greetings card, sent in New Zealand in 1912 
It has long been recognised that one of the repercussions of romantic self-expression was the loss of a common artistic language. ${ }^{59}$ Recently, scholars like Nicola Brown and Sonia Solicari have made the case for sentimental art being an attempt to rectify this by creating a defined language intended to communicate emotion. ${ }^{60}$ It used not only defined symbols like those shown in the postcards, but also metaphors like touch, (as in figure 8, which is heavily embossed to reinforce the sense of presence mentioned in the text) ${ }^{61}$ Problems arise, however, when we expect such a work to be an expression or exploration of the creator's psychological state. ${ }^{62}$ Art, under the Romantic model, may be an acceptable vehicle for emotion. ${ }^{63}$ In a model based on expressive individualism, however, calculated prefabrication (of text or image) is incompatible with the idea of genuine expression of emotion. ${ }^{64}$

In the final chapter of Cult of the Factish Gods, Bruno Latour examines love language, and argues that there is no earthly point in trying to be original when saying something like "I love you." It is not simply an expression of emotion. It is, he argues, a container that aims to transform the experience of the recipient. It should be judged not on originality, but on its tone, and its ability to move the participants "from distance to proximity," and also to bring them more into the present. ${ }^{65}$ This is exactly what the images and poetry on Hands Across the Sea cards like the ones studied here do. They lessen emotional distance, create an emotional response, and update the relationship (which effectively has not moved since last contact) into the present.

Latour's ideas of transformative language are also congruent with those of David Gerber, who sees letters as tools for transforming old relationships, and Daniel M. Gross, for whom emotions are a socially-defined rhetorical category. ${ }^{66}$ The idea of emigrant letters as having a rhetorical function is not new. ${ }^{67}$ Nevertheless, thinking of pre-printed postcards as emotional rhetoric reinforces the idea that they are primarily a form of persuasion - making a case for the strength and durability of the relationship.

If one follows Keith Oatley's definition of emotional terminology, "emotions" themselves have a short duration. "Moods" last longer, while the most durable emotions are termed "sentiments." These latter "form the central bases of a relationship over many years."68 It seems, therefore, that using sentimental means for arguments aimed at having long-lasting emotional results is entirely appropriate. Not that all Edwardian postcards were sentimental. Tourist views, for example, generally functioned as baseline reminders of regard. Nor can one be sure that every user of sentimental cards necessarily intended to activate the cards' emotional language. Nevertheless, buying a Hands Across the Sea card, with its emotionally abundant visual and verbal tropes, represented a conscious choice on the part of the purchaser. It makes sense for emigrants and those at a distance who wanted to generate a greater impact to select such cards and to frame their arguments for continued commitment using emotionally overt means. We should therefore not discount the potential evidence from sentimental genres like Hands Across the Sea cards when trying to understand the Edwardian emotional landscape. And this idea about short term emotions and long-term sentiments helps to explain why many card users allowed their own written texts to use a different tone to those of the cards' design. The everyday voice, like that used by Lil, maintained a relatively stoic attitude that presented the emotional state as being normal, so as not to upset the recipient, whilst the design is able to argue strongly for the long-term strength of the relationship.

It is interesting, by contrast, to see what happens when both parties know that the everyday is not safe. Michael Roper studied cards sent by soldiers in the First World War, and he similarly noted the dual use of text and pre-printed elements in this context. However, in Roper's cards the stoic, heroic images of soldiers on the front allowed certain emotionally vulnerable sentiments to be conveyed within the handwritten text. ${ }^{69}$ The hard task of showing the stoic everyday is thus devolved to the card designer, whilst the messages use emotion rather than sentiment as a rhetorical tactic in order to impress the importance of the relationship right 
now. For people unsure about having a future, articulating the relationship as it stands in the present would be the most important emotional part of what Roper terms "impression management," as the soldiers tried to negotiate their relationships from afar. ${ }^{70}$

\section{Conclusion}

The act, whether in war or peace, of selecting a postcard with a pre-packaged greetings design was still emotionally resonant. This paper has shown examples that represent the many people who were attentive to the designs on the greetings postcards they sent, and to the way they could recharge a relationship, replenish memory and renew a sense of intimacy and presence with the recipient. They did this by visually making a sentimental case for the abundance of the sender's regard for the recipient and their desire for the continuance of the relationship. Yet precisely because the design was prefabricated, there was no direct evidence (as there would be in the handwritten message) that could be used to interpret emotional vulnerability on the sender's part. The emotionally understated handwritten texts thus downplayed self in order to project a sense of attentiveness to the recipient and the relationship. If we can conclude anything from the preceding study, it is that the postcard allowed people to keep a foot in both emotional regimes. The individual could project themselves in the text as self-sufficiently stoic, whilst freely sharing feeling via the images as a rhetorical tactic, albeit one that should not necessarily be understood in expressive terms. There is a much larger history, yet to be written, of the wider epistolary practices of emotion, both those of New Zealand immigrants and those in the wider diaspora. The more modest aim of this paper has been to draw attention both to the fact that the epistolary category needs to be expanded to include both visual and verbal emotional rhetoric, and that the ways these modes coalesce serves to provide a more nuanced view of Edwardian emotional styles.

\footnotetext{
${ }^{1}$ Jock Phillips and Terry Hearn, Settlers: New Zealand Immigrants from England, Ireland and Scotland 1800-1945 (Auckland: Auckland University Press, 2008), 45.

${ }^{2}$ Angela McCarthy, "Migration and Ethnic Identities in the Nineteenth Century," in The New Oxford History of New Zealand, ed. Giselle Byrnes (Melbourne: Oxford University Press, 2009), 185.

${ }^{3}$ David Gerber, for example, discusses the centrality of letters within what he calls the "culture of emigration." David A. Gerber, "Epistolary Ethics: Personal Correspondence and the Culture of Emigration in the Nineteenth Century," Journal of American Ethnic History 19, no. 4 (2000): 6. Perhaps the classic text on how letters functioned in this regard is David Fitzpatrick, Oceans of Consolation: Personal Accounts of Irish Migration to Australia (Ithaca, NY: Cornell University Press, 1994).

${ }^{4}$ Kate Hunter gives a good overview of the literature on war correspondence. Kate Hunter, "More than an Archive of War: Intimacy and Manliness in the Letters of a Great War Soldier to the Woman He Loved, 1915-1919," Gender \& History 25, no. 2 (2013): 339-41. Porter and Macdonald mention the role of letters in maintaining emotional ties, but emotional reactions are not discussed as a broader theme. Frances Porter and Charlotte Macdonald, ed., My Hand will Write what my Heart Dictates: The Unsettled Lives of Women in Nineteenth-Century New Zealand as Revealed to Sisters, Family and Friends (Auckland: Auckland University Press, 1996), 12; 58.

${ }^{5}$ This study uses, and illustrates, cards collected by the author in New Zealand, from largely Internet (and a few retail) sources. It was felt that these would better reflect broader postcard usage than relying on archival collections, gifted by an atypical segment of the population. See Peter Gilderdale, "Hands Across the Sea: Situating an Edwardian Greetings Postcard Practice" (Ph.D. thesis, Auckland University of Technology, 2013), 334. Another PhD postcard researcher independently opted to study cards from auction sites for the same reasons. Daniel Gifford, "To You and Your Kin: Holiday Images
} 
from America's Postcard Phenomenon, 1907-1910" (Ph.D. thesis, George Mason University, 2011), 26.

${ }^{6}$ David A. Gerber, "Acts of Deceiving and Withholding in Immigrant Letters: Personal Identity and Self-Presentation in Personal Correspondence," Journal of Social History 39, no. 2 (2005): 318.

${ }^{7}$ Gross, for example contrasts these, with a strong preference for the latter. Daniel M. Gross, The Secret History of Emotion: From Aristotle's Rhetoric to Modern Brain Science (Chicago, IL: University of Chicago Press, 2006). Reddy attempts to bridge the gap, by postulating the idea of "emotives," which bridge the nature / nurture divide. William M. Reddy, The Navigation of Feeling: A Framework for the History of Emotions (Cambridge: Cambridge University Press, 2001), 320-30.

${ }^{8}$ Linda M. Austin, Nostalgia in Transition, 1780-1917 (Charlottesville: University of Virginia Press, 2007), 81. On the early development of this usage, see David Lowenthal, "Past Time, Present Place: Landscape and Memory," Geographical Review 65, no. 1 (1975): 1, and Michael Roper, "Nostalgia as an Emotional Experience in the Great War," The Historical Journal 54, no. 2 (2011): 423.

${ }^{9}$ Lauren Berlant, "Intuitionists: History and the Affective Event," American Literary History 20, no. 4 (2008): 858 .

${ }^{10}$ Erik Olssen, "Families and Gendering of European New Zealand in the Colonial Period, 1840-80," in The Gendered Kiwi, ed. Caroline Daley and Deborah Montgomerie (Auckland: Auckland

University Press, 1999), 47.

${ }^{11}$ Gerber, "Epistolary Ethics," 8.

${ }^{12}$ Reddy, The Navigation of Feeling: A Framework for the History of Emotions, 258-9. Reddy does not identify Stoicism per se, but for a detailed discussion of the influence of stoicism, and particularly the stoic Emperor Marcus Aurelius, on Victorian Britain, see Lee Behlman, "The Victorian Marcus Aurelius: Mill, Arnold, and the Appeal of the Quasi-Christian," Journal of Victorian Culture 16, no. 1 (2011): 1-24.

${ }^{13}$ Carolyn Burdett, "Is Empathy the End of Sentimentality?," Journal of Victorian Culture 16, no. 1 (2011): 259-61.

${ }^{14}$ Reddy, The Navigation of Feeling, 312.

${ }^{15}$ This trajectory is supported by comparative linguistic usage. Usage of the word "sentimental" increased steadily until a peak around 1930, and overtook "fortitude" in the 1880's. "Courage" was more used than either throughout the nineteenth century, but tracked steadily downwards through the century in tandem with the word "sentiment," whilst "sentimental" rose in use. Words like "stoical" and "stoic" were less common, showing little variation in frequency through the period. These results were found using Google Ngram Viewer. https://books.google.com/ngrams While results should not be taken too definitively (one cannot tell the context or tone in which words were used, and it can be difficult to select the words most typical of a period's expression of a particular idea), they can be useful in tandem with other sources. In this case, the word "courage" does not figure heavily in an overall search, but is much higher when looking at both British and American results singly, and in a search of British literature. On the methodological aspects of using Ngram, see Frederick W. Gibbs and Daniel J. Cohen, "A Conversation with Data: Prospecting Victorian Words and Ideas," Victorian Studies 54, no. 1 (2011): 69-77.

${ }^{16}$ In relation to the family unit, Erik Olssen points out that the idea of a single Victorian family structure amongst immigrants to New Zealand is illusory, with varying practices across multiple categories, notably class, religion and locality. Olssen, "Families and Gendering of European New Zealand," 38.

${ }^{17}$ Julie-Marie Strange, "'She Cried a Very Little': Death, Grief and Mourning in Working-Class Culture, c. 1880-1914," Social History 27, no. 2 (2002): 148; Keith Oatley, Emotions: A Brief History (Malden, MA: Blackwell, 2004), 34. Oatley notes that researchers have found evidence that gender stereotypes play out in reality, but regards this as culturally rather than genetically derived.

${ }^{18}$ John Tosh, A Man's Place: Masculinity and the Middle-Class Home in Victorian England (New Haven, CT: Yale University Press, 1999), 97-100.

${ }^{19}$ Ibid., 193-94. For a discussion on models of manhood, see Martin Francis, "The Domestication of the Male? Recent Research on Nineteenth- and Twentieth-Century British Masculinity," The

Historical Journal 45, no. 3 (2002): 643-44. 
${ }^{20}$ Jock Phillips, A Man's Country? The Image of the Pakeha Male - a History (Auckland: Penguin, 1987), 38. Olssen's note of caution about singular structures in the family (see note 16), can be usefully extended to issues of male emotion. Too little research has been done on this area to allow secure generalisations.

${ }^{21}$ On the literature around this, see Strange, "'She Cried a Very Little,"' 143.

${ }^{22}$ Pierre Bourdieu, Distinction: A Social Critique of the Judgement of Taste, trans. Richard Nice

(Cambridge, MA: Harvard University Press, 1984), 379. See also Sonia Solicari, "Selling Sentiment:

The Commodification of Emotion in Victorian Visual Culture," 19: Interdisciplinary Studies in the Long Nineteenth Century 4 (2007): 14.

${ }^{23}$ Strange, "'She Cried a Very Little,"' 148 . This sense of language's inadequacy in relation to emotion may relate to our brain's structure. Psychologists note that our experience of emotions occurs in the limbic layer of the brain, whereas language is a function of the neocortex. Oatley, Emotions: A Brief History, 67.

${ }^{24}$ Tanja Bueltmann, Scottish Ethnicity and the Making of New Zealand Society, 1850-1930 (Edinburgh: Edinburgh University Press, 2011), 61.

${ }^{25}$ Gerber, "Epistolary Ethics," 15.

${ }^{26}$ Porter and Macdonald, My Hand will Write what my Heart Dictates, 5. On displacement, see page

3 , and on the socio-economic status of the writers of these letters, see page 15.

${ }^{27}$ Julie-Marie Strange, Death, Grief and Poverty in Britain, 1870-1914 (Cambridge: Cambridge University Press, 2005), 208. Michael Roper notes this same concern amongst soldiers away from home during the First World War. Roper, "Nostalgia as an Emotional Experience in the Great War," 441.

${ }^{28}$ This process of confirmation had taken eleven months in the 1850's. Porter and Macdonald, $M y$

Hand will Write what my Heart Dictates, 12.

29 "Inauguration of Penny Postage," Evening Post, 2 January, 1901, 6. While newspapers are now more readily accessible, the most authoritative and painstakingly researched book on the everevolving New Zealand postcard legislation is Alan Jackson, New Zealand Postcards: Rates \& Regulations to 1939 (Auckland: Postal History Society of New Zealand, 1984).

${ }^{30}$ Julia Gillen, "Writing Edwardian Postcards," Journal of Sociolinguistics 17, no. 4 (2013): 489.

31 "Town \& Country," Timaru Herald, 24 February, 1898, 2.

${ }^{32}$ Bjarne Rogan, "An Entangled Object: The Picture Postcard as Souvenir and Collectible, Exchange and Ritual Communication," Cultural Analysis 4 (2005): 18.

${ }^{33}$ Gillen, "Writing Edwardian Postcards," 506.

${ }^{34}$ Frank Staff, The Penny Post: 1680-1918 (London: Lutterworth, 1964), 53.

${ }^{35}$ On this, see Julia Gillen and Nigel Hall, "Any Mermaids? Early Postcard Mobilities," in Mobile Methods, ed. Monika Büscher, John Urry, and Katian Witchger (Hoboken, NJ: Routledge, 2010), and Gilderdale, "Hands Across the Sea," 242-316.

${ }^{36}$ The classic overviews of this phenomenon from a British perspective are Richard Carline, Pictures in the Post: The Story of the Picture Postcard (Bedford, UK: Fraser, 1959), and Frank Staff, The

Picture Postcard and Its Origins, 2nd ed. (London: Lutterworth 1979). The history of the New Zealand postcard is dealt with most comprehensively by William Main and Alan Jackson, "Wish You Were Here": The Story of New Zealand Postcards (Nelson: New Zealand Postcard Society, 2004).

${ }^{37}$ In the course of researching this genre I have collected over 2000 different designs, and estimate that this is perhaps a third of those created. Over 100 different manufacturers created versions of this card.

${ }^{38}$ Gillen, "Writing Edwardian Postcards," 505. She notes that it is harder to interpret what may have motivated the selection of card with some other genres, such as the typical view card.

39 "Amusements," Auckland Star, August 28, 1903, 8. On this play, see Gilderdale, "Hands Across the Sea: Situating an Edwardian Greetings Postcard Practice," 94-98.

${ }^{40}$ A newspaper article discussing postcard fashions describes Christmas postcards as a "form of melodrama." "Christmas Cheer and Otherwise," Evening Post (Wellington), November 30, 1908, 8.

${ }^{41}$ Hunter, "More than an Archive of War," 347.

${ }^{42}$ Solicari, "Selling Sentiment," 1.

${ }^{43}$ This card was published by Raphael Tuck, and is in the author's collection. 
${ }^{44}$ All the cards illustrated and quoted here come from the author's collection. Postcard users frequently skimped on punctuation - another case where they have much in common with Twitter.

${ }^{45}$ An example of the language of flowers in action is Kate Greenaway and Jean Marsh, The

Illuminated Language of Flowers (London: MacDonald and Jane's, 1978 [1884]). For an example that makes its communicative function particularly clear, see Daniel Wuebben, "Captain Frederick Marryat and the Floral Telegraph; or, a Forgotten Coder and His Floral Code," Victorian Literature and Culture 42, no. 2 (2014).

${ }^{46}$ Gilderdale, "Hands Across the Sea," 435-36.

${ }^{47}$ Gerber, "Epistolary Ethics," 11.

${ }^{48}$ Karen Walker, "'Always There for Me': Friendship Patterns and Expectations among Middle- and Working-Class Men and Women," Sociological Forum 10, no. 2 (1995): 293.

${ }^{49}$ See, for example, Glyn Harper, ed. Letters from the Battlefield: New Zealand Soldiers Write Home 1914-18 (Auckland: HarperCollins, 2001), 38-39.

${ }^{50}$ Hunter, "More than an Archive of War," 344. Although many writers on postcards define the difference between postcards and letters as being that one is open (public) and the other enclosed (private), this does not play out so clearly in practice. Postcard users during this period increasingly used envelopes for postcard messages. On the reasons for this, see Gilderdale, "Hands Across the Sea," 317-22.

${ }^{51}$ These were identified from a set of 600 cards which I examined for my Ph.D., and all of which remain in my own collection. These cards were sourced in New Zealand, and therefore contained more cards sent from overseas than from New Zealand immigrants writing home. Doubtless many more were from such sources, however sender and destination details are not given on all postcards especially those with longer texts that fill the whole card.

${ }^{52}$ On the literature around gendered use of postcards, see Gilderdale, "Hands Across the Sea," 473-77.

${ }^{53}$ William Isaac Thomas and Florian Znaniecki, The Polish Peasant in Europe and America, vol. 1

(New York: Dover, 1958), 303-05.

${ }^{54}$ Emily West, "Expressing the Self through Greeting Card Sentiment," International Journal of Cultural Studies 13, no. 5 (2010): 253-54.

${ }^{55}$ Kathryn Dindia et al., "The Function of Holiday Greetings in Maintaining Relationships," Journal of Social and Personal Relationships 21, no. 5 (2004): 578.

${ }^{56}$ Fitzpatrick, Oceans of Consolation, 21. In this regard he cites Arnold Schrier, Ireland and the American Emigration, 1850-1900 (Minneapolis: University of Minnesota Press, 1958).

${ }^{57}$ See, for example, Stephen Papson, "From Symbolic Exchange to Bureaucratic Discourse: The Hallmark Greeting Card," Theory, Culture \& Society 3, no. 2 (1986).

${ }^{58}$ West, "Expressing the Self through Greeting Card Sentiment," 253-54.

${ }^{59}$ See, for example, Lorenz Eitner, "The Open Window and the Storm-Tossed Boat: An Essay in the Iconography of Romanticism," The Art Bulletin 37, no. 4 (1955): 282.

${ }^{60}$ Nicola Brown, "Tender Beauty: Victorian Painting and the Problem of Sentimentality," Journal of Victorian Culture 16 (2011): 220, and Solicari, "Selling Sentiment: The Commodification of Emotion in Victorian Visual Culture," 1.

${ }^{61}$ David Gerber notes this haptic effect in relation to handwriting, and the paper of letters, which been touched by the sender. Gerber, "Epistolary Ethics," 14. Embossing cards serves to heighten this effect.

${ }^{62}$ On the background to this model, see Oatley, Emotions: A Brief History, 13-14.

${ }^{63}$ Reddy, The Navigation of Feeling: A Framework for the History of Emotions, 258-59.

${ }^{64}$ West, "Expressing the Self through Greeting Card Sentiment," 453.

${ }^{65}$ Bruno Latour, On the Modern Cult of the Factish Gods, trans. Catherine Porter and Heather

Maclean (Durham: Duke University Press, 2010), 102-04.

${ }^{66}$ Gerber, "Epistolary Ethics," 5, and Gross, The Secret History of Emotion.

${ }^{67}$ Fitzpatrick, Oceans of Consolation, 22.

${ }^{68}$ Oatley, Emotions: A Brief History, 4.

${ }^{69}$ Roper, "Nostalgia as an Emotional Experience in the Great War," 430-31.

${ }^{70}$ Ibid., 437. Kate Hunter documents a set of letters that dealt with this differently, by strongly imagining a future, as well as discussing the present state of the relationship. Hunter, "More Than an Archive of War," 347-51. 